Patient Survey

\title{
Demographic Factors Associated with Patient-Reported Outcome Measures in Pain Management
}

Jihad Abdelgadir, MD1, Edmund W Ong, PhD², Salma M Abdalla, MD³, John C Hunting, MPH², Mohamed Mustafa Diab, MD, Michael M Haglund, MD, PhD', C Rory Goodwin, MD, PhD ${ }^{1}$, Amanda Nelli, MD², and Padma Gulur, MD²

From: ${ }^{1}$ Department of Neurosurgery, Duke University Medical Center, Durham, NC; 2Department of Anesthesiology, Duke University Medical Center, Durham, NC; ${ }^{3}$ Department of Epidemiology, Boston University, Boston, MA; ${ }^{4}$ Philip R. Lee Institute for Health Policy Studies, University of California San Francisco, San Francisco, CA

Address Correspondence: Padma Gulur, MD Department of Anesthesiology Duke University Medical Center, Box 3094 MS \#5 Durham, NC 27710 E-mail:

padma.gulur@duke.edu

Disclaimer: There was no external funding in the preparation of this manuscript. Conflict of interest: Each author certifies that he or she, or a member of his or her immediate

family, has no commercial association (i.e., consultancies, stock ownership, equity interest, patent/licensing arrangements, etc.) that might pose a conflict of interest in connection with the submitted manuscript.

Manuscript received: 03-07-2019

Revised manuscript received: o6-19-2019

Accepted for publication: o6-21-2019

Free full manuscript: www.painphysicianjournal.com
Background: Pain control is strongly correlated with the Hospital Consumer Assessment of Healthcare Providers and Systems (HCAHPS) quality-of-care domains and overall hospital experience. Prior research implicates several factors in the variability of patients' pain management satisfaction scores, including but not limited to racial diversity, ethnic diversity, gender, socioeconomic status, and other cultural factors.

Objective: In this study, we examined responses to the HCAHPS survey in order to assess factors associated with patient-reported experiences of pain management.

Study Design: The study design involved a retrospective analysis of patient survey responses.

Setting: The research took place at a university-affiliated tertiary hospital.

Methods: The study was conducted in a university-affiliated tertiary hospital. Records for adult patients discharged between October 2015 and June 2017 were included. We obtained all patient responses to the HCAHPS pain management questions. We then performed a systematic statistical analysis to evaluate interactions between demographic factor variables and responses to the HCAHPS pain management questions.

Results: Between October 2015 and June 2017, 107,287 patients were discharged from the hospital. Of these, 13,026 of the respondents answered at least one of the HCAHPS pain management questions.

Among HCAHPS pain-domain respondents, "Hispanic" and "Black or African American" respondents are more likely to report successful Pain Control when compared to "Not Hispanic" and "Caucasian/White," respectively (odds ratios [ORs] 1.60, 1.22). Additionally, among women, "Black or African American" respondents are more likely to report positive Staff Helpfulness than "Caucasian/White" respondents (OR 1.38).

However, we also identified corresponding associations among HCAHPS pain-question responding and patient race/ethnicity: "Hispanic" and "Black/African American" patients were each less likely to respond to the HCAHPS pain questions (ORs 2.03, 2.74)

Limitations: The primary limitation to this study was nonresponse bias; nevertheless, this is likely to be similar to bias experienced at other institutions. Additionally, this is a single institution study; however, given that the institution has a very large catchment area, we believe the results could be generalized to other settings.

Conclusion: Response rates and responses to HCAHPS pain questions vary by race/ethnicity and sex. It appears likely that Hispanic and Black/African American patients underreport negative experiences. As HCAHPS surveys are used to inform decision-making within the US health care system, demographic biases in the survey data could lead to biases in care and resource allocation.

Key words: Pain, HCAHPS, patient reported outcome measures, patient satisfaction, ethnicity, race

Pain Physician 2020: 23:17-24 
P atient-reported outcome measures and patient satisfaction are strongly correlated with better clinical outcomes and improved quality of care (1-3). The Centers for Medicare and Medicaid Services (CMS) uses satisfaction reports as a metric to assess the quality of care delivered and the performance of individual hospitals (4-6). The Hospital Consumer Assessment of Healthcare Providers and Systems (HCAHPS) survey serves as the primary national tool to measure patients' perception of their hospital experience. HCAHPS assesses 8 main domains of hospital care quality including communication with nurses and doctors, responsiveness of hospital staff, pain management, cleanliness and quietness, communication about medication, discharge information, and overall hospital score (7). In the hospital value-based purchasing program (6), the scores obtained from HCAHPS account for $30 \%$ of the total performance score used for an individual hospital's Medicare and Medicaid reimbursement.

Pain has played a critical role in overall patient satisfaction since the 1990s, after the American Pain Society initiated the "Pain, the fifth vital sign" campaign, raising awareness among health care professionals of pain assessment and management (8). As a result of this campaign, large regulatory bodies including the Veterans Health Administration (VHA) and Joint Commission on the Accreditation of Healthcare Organizations (JCAHO) mandated pain assessment and treatment of all patients $(9,10)$.

Question 14 in the HCAHPS survey is intended to evaluate patients' experience of their pain management (6). Pain control is strongly correlated with other HCAHPS quality-of-care domains and overall hospital experience $(3,11)$. Prior research implicates several factors in the variability of patients' pain management satisfaction scores, including, but not limited to, racial/ethnic diversity, gender, socioeconomic status, and other cultural factors $(12,13)$. Multiple studies demonstrate that racial and ethnic differences influence health outcomes, access to care, health care utilization, and the perception of hospital experience (14-18). Here, we examine demographic associations with patient-reported outcomes of pain management.

\section{Methods}

\section{Sample}

The sample was obtained from a large (957-bed) tertiary care center affiliated with a large academic institution. This care center is located in an urban area, receiving patients from a wide radius and caring for a diverse population of patients from various ethnic and racial backgrounds. Records for all adult patients discharged from the University Hospital between October 2015 and June 2017, inclusive, were included in this study. Records included patient responses (if any) to the 2 pain-domain HCAHPS questions and patient-reported demographic factors (sex, race, and ethnicity).

\section{HCAHPS Surveys}

The University Hospital attempts to collect HCAHPS survey responses from all eligible adult patients. Inclusion criteria are: discharged nonpsychiatric patients age 18 years or older who had at least one overnight stay in the hospital. Exclusion criteria are: patients discharged to hospice care, nursing home, or skilled nursing facility; court/law enforcement patients; and no-publicity patients (19).

HCAHPS-eligible patients are sampled by one of 2 methods. First, a random sample of eligible discharges is drawn on a monthly basis for inclusion in the officially-reported HCAHPS sample. CMS services mandates that hospitals must obtain at least 300 completed HCAHPS surveys over the 12-month reporting period (19). Per CMS, patients included in this sample are mailed paper copies of the HCAHPS survey to complete. These patients are contacted at the mailing address they provided upon admission. Second, after the officially-reported HCAHPS sample is chosen randomly from among eligible discharges, all remaining eligible patients are solicited to complete an internet-based HCAHPS survey. These patients are contacted at the email address they provided upon admission.

The responses to the HCAHPS pain-domain questions were extracted for this study. The HCAHPS instruments in use during this time period included 2 questions on pain management: (a) "During this hospital stay, how often was your pain well controlled?" (hereafter "Pain Control") and (b) "During this hospital stay, how often did the hospital staff do everything they could to help you with your pain?" (hereafter "Staff Helpfulness"). The available answer choices for these questions were: "Never," "Sometimes," "Usually," or "Always." Customary interpretation of these questions collapses responses to a binary. Only responses with "Always" are considered positive (success); all other answer choices are considered negative (failure). The study was approved by the Institutional Review Board. 


\section{Statistical Analysis}

Descriptive statistics for patient demographics were calculated at baseline and presented as mean (standard deviation [SD]) for continuous variables and frequency (percentage) for categorical variables (Table 1). The outcome variables for this study are HCAHPS pain management and staff satisfaction. To identify predictors for these outcomes, we first used a log-linear model to determine the relationships among the 5 categorical variables (gender, race, ethnicity, pain control, and staff helpfulness) and all of their interaction terms. A saturated model was built with all 5 variables and all interaction terms. The most nonsignificant term was removed at each iteration in hierarchical manner. We used likelihood ratio (LR) tests to compare the 2 models before and after each term removal. The final log-linear model was determined based on a significant LR test comparing the new and previous model $(P<.05)$. We also tested the goodness of fit of the final model by comparing it to the saturated model using the LR test.

For each outcome of interest, we performed univariate logistic regression by including the terms that interact with the outcome variable in the final log-linear model. Multiple-level categorical variables (e.g., race) were tested for their global effects as well as individuallevel comparisons to the reference group. In the case of a 3- or more-way interaction with the outcome variable in the final log-linear model, a multivariable logistic model was built to determine global effects and was followed by stratified univariable logistic regression models. As a supplemental analysis, all baseline demographic variables and outcome variables (pain control and staff helpfulness) were compared between participants who responded to any part of the survey versus those who did not. Statistical significance was determined based on $P<$ .05. All analyses were performed by SAS Version 9.4 (SAS Institute, Inc., Cary, NC), and R Version 3.4.3.

\section{RESULTS}

There were a total of 107,287 adult patients discharged from the university hospital between October 2015 and June 2017, inclusive. Of these, 13,026 survey respondents answered at least one of the pain management questions during the study period.

The 5-way log-linear analysis produced a final model that retained all effects:

Ethinicity + Race + Gender + Pain Control + Staff helpfulness + (Ethnicity:Race) + (Pain Control:Staff Helpfulness) + (Ethnicity:Pain Control) + (Race:Pain Control) + (Race:Staff Helpfulness)
Table 1. Survey responding patient demographics.

\begin{tabular}{|c|c|}
\hline \multicolumn{2}{|c|}{ Demographic Table among Responders } \\
\hline & $\begin{array}{c}\text { Total } \\
(\mathbf{n}=\mathbf{1 3 0 2 6})\end{array}$ \\
\hline \multicolumn{2}{|l|}{ Ethnicity } \\
\hline Not Hispanic/Latino & $12416(95.32 \%)$ \\
\hline Hispanic & $255(1.96 \%)$ \\
\hline Not Reported & $355(2.73 \%)$ \\
\hline \multicolumn{2}{|l|}{ Race } \\
\hline Caucasian/White & $10103(77.56 \%)$ \\
\hline Black or African American & $2206(16.94 \%)$ \\
\hline Asian & $176(1.35 \%)$ \\
\hline American Indian or Alaskan Native & $57(0.44 \%)$ \\
\hline Native Hawaiian or Other Pacific Islander & $7(0.05 \%)$ \\
\hline Other & $153(1.17 \%)$ \\
\hline Unknown & $149(1.14 \%)$ \\
\hline 2 or more races & $175(1.34 \%)$ \\
\hline \multicolumn{2}{|l|}{ Gender } \\
\hline Female & $7465(57.31 \%)$ \\
\hline Male & $5561(42.69 \%)$ \\
\hline \multicolumn{2}{|l|}{ Pain Control } \\
\hline Pain Always Controlled & $8261(63.69 \%)$ \\
\hline Pain Not Controlled & $4710(36.31 \%)$ \\
\hline Missing & $55(. \%)$ \\
\hline \multicolumn{2}{|l|}{ Staff Helpfulness Level } \\
\hline Staff Always Helpful & $10515(81.33 \%)$ \\
\hline Staff Not Always Helpful & $2414(18.67 \%)$ \\
\hline Missing & $97(. \%)$ \\
\hline
\end{tabular}

Of interest, 3 of the demographic-response interactions were statistically significant: Race:Gender:Staff Helpfulness $(P=.014)$, Race:Pain Control $(P=.001)$, and Ethnicity:Pain Control $(P=.004)$. To break down the Race:Gender:Staff Helpfulness interaction, chi-square tests on Race and Staff Helpfulness variables were performed separately by gender. For women, there was a significant association between Race and Staff Helpfulness $(P<.001)$; this was not the case for men $(P=.10)$.

For the Race:Gender:Staff Helpfulness interaction among women, staff helpfulness was examined in each group of Race in reference to "Caucasian/White." Odds ratios indicated that the odds of reporting positive Staff Helpfulness were 1.38 times higher for "Black or African American" respondents (95\% confidence interval $[\mathrm{Cl}], 1.18-1.62)$ than for "Caucasian/White" respondents (Table 3). 
Pain Physician: January/February 2020; 23:17-24

Table 2. Investigation into demographic associations with Pain Control.

\begin{tabular}{|c|c|c|c|c|c|}
\hline \multicolumn{6}{|c|}{ Investigated Associations with Pain Control } \\
\hline & $\begin{array}{c}\text { Total } \\
(\mathrm{n}=\mathbf{1 2 9 7 1})\end{array}$ & $\begin{array}{c}\text { Pain Not Always } \\
\text { Controlled } \\
(\mathbf{n}=\mathbf{4 7 1 0})\end{array}$ & $\begin{array}{c}\text { Pain Always } \\
\text { Controlled } \\
(\mathbf{n}=\mathbf{8 2 6 1})\end{array}$ & OR (95\% CI) & $P$ value \\
\hline Ethnicity & & & & & 0.004 \\
\hline Not Hispanic/Latino & $12366(95.34 \%)$ & $4519(95.94 \%)$ & $7847(94.99 \%)$ & Reference & -- \\
\hline Hispanic & $253(1.95 \%)$ & $67(1.42 \%)$ & $186(2.25 \%)$ & $1.60(1.21,2.12)$ & 0.001 \\
\hline Not Reported & $352(2.71 \%)$ & $124(2.63 \%)$ & $228(2.76 \%)$ & $1.06(0.85,1.32)$ & 0.61 \\
\hline Race & & & & & 0.001 \\
\hline Caucasian/White & $10068(77.62 \%)$ & $3748(79.58 \%)$ & $6320(76.50 \%)$ & Reference & \\
\hline Black or African American & $2192(16.90 \%)$ & $716(15.20 \%)$ & $1476(17.87 \%)$ & $1.22(1.11,1.35)$ & $<0.001$ \\
\hline 2 or more races & $172(1.33 \%)$ & $61(1.30 \%)$ & $111(1.34 \%)$ & $1.08(0.79,1.48)$ & 0.64 \\
\hline American Indian or Alaskan Native & $57(0.44 \%)$ & $14(0.30 \%)$ & $43(0.52 \%)$ & $1.82(1.00,3.33)$ & 0.052 \\
\hline Asian & $175(1.35 \%)$ & $71(1.51 \%)$ & $104(1.26 \%)$ & $0.87(0.64,1.18)$ & 0.36 \\
\hline Native Hawaiian or Other Pacific Islander & $7(0.05 \%)$ & $2(0.04 \%)$ & $5(0.06 \%)$ & $1.48(0.29,7.65)$ & 0.64 \\
\hline Other & $152(1.17 \%)$ & $46(0.98 \%)$ & $106(1.28 \%)$ & $1.37(0.97,1.94)$ & 0.08 \\
\hline Unknown & $148(1.14 \%)$ & $52(1.10 \%)$ & $96(1.16 \%)$ & $1.10(0.78,1.54)$ & 0.60 \\
\hline
\end{tabular}

For the Race:Pain Control interaction, pain control was examined in each group of Race in reference to "Caucasian/White." Odds ratios indicated that the odds of reporting positive Pain Control were 1.22 times higher for "Black or African American" respondents (95\% $\mathrm{Cl}, 1.11-1.35)$ than for "Caucasian/White" respondents (Table 2).

For the Ethnicity:Pain Control interaction, "Hispanic" and "Not Hispanic" levels of Ethnicity were compared with "Not Hispanic" as the reference. Odds ratios indicated that the odds of reporting positive Pain Control were 1.60 times higher for "Hispanic" respondents $(95 \% \mathrm{Cl}, 1.20-2.15)$ than for "Not Hispanic" respondents (Table 2).

These analyses suggest that, among HCAHPS paindomain respondents, "Hispanic" and "Black or African American" respondents are more likely to report successful Pain Control when compared to "Not Hispanic" and "Caucasian/White," respectively. Additionally, among women, "Black or African American" respondents are more likely to report positive Staff Helpfulness than "Caucasian/White" respondents.

Demographic distributions across HCAHPS paindomain respondents and nonrespondents were analyzed. All discharged patients were categorized (Response) as either having responded to at least one pain-domain question (Respondents, $n=13,026$ ) or not having responded to either pain-domain question (Nonrespondents, $n=94,261$ ). Data are reported in
Table 4. There were significant associations between both Race and Response $(P<.001)$ and between Ethnicity and Response $(P<.001)$. Follow-up analyses were performed corresponding to those completed above. "Black or African American" patients were 2.74 times less likely to respond to HCAHPS pain questions than "Caucasian/White" patients $(95 \% \mathrm{Cl}, 2.61-2.88)$. "Hispanic" patients were 2.03 times less likely to respond to HCAHPS pain questions than "Not Hispanic" patients (95\% Cl, 1.78-2.31).

\section{Discussion}

Here, we report 2 principal, high-level findings: (a) among respondents to HCAHPS pain questions, rates of patient-reported successful pain control and positive staff helpfulness varied by patient race/ethnicity; and (b) response rates to those HCAHPS pain questions also varied by the same patient race/ethnicity factors.

Specifically, among respondents to HCAHPS pain questions: Hispanic and Black/African American patients were each more likely to report successful pain control; and female Black/African American patients were more likely to report positive staff helpfulness.

Patient-reported outcome measures, such as those in the HCAHPS survey, are shown to be strongly correlated with clinical outcomes and quality of care (1-3). Furthermore, the pain control domain is shown to be strongly correlated with other HCAHPS quality-of-care domains and overall hospital experience. 
Demographic Factors and Pain Management

Table 3. Investigation into three-way interaction term, Sex*Race* Staff Helpfulness.

\begin{tabular}{|l|c|c|c|c|c||}
\hline \multicolumn{5}{|c||}{ Investigation into Staff Helpfulness by Race, among Females } \\
\hline & $\begin{array}{c}\text { Total } \\
(\mathbf{n}=\mathbf{7 4 1 6})\end{array}$ & $\begin{array}{c}\text { Staff Not } \\
\text { Always Helpful } \\
(\mathbf{n}=\mathbf{1 4 5 4})\end{array}$ & $\begin{array}{c}\text { Staff Always } \\
\text { Helpful } \\
(\mathbf{n}=\mathbf{5 9 6 2})\end{array}$ & OR (95\% CI) & P-value \\
\hline Race & \multicolumn{3}{|c|}{} & 0.004 \\
\hline Caucasian/White & $5544(74.76 \%)$ & $1132(77.85 \%)$ & $4412(74.00 \%)$ & Reference & -- \\
\hline Black or African American & $1393(18.78 \%)$ & $218(14.99 \%)$ & $1175(19.71 \%)$ & $1.38(1.18,1.62)$ & $<0.001$ \\
\hline 2 or more races & $122(1.65 \%)$ & $30(2.06 \%)$ & $92(1.54 \%)$ & $0.79(0.52,1.19)$ & 0.26 \\
\hline American Indian or Alaskan Native & $26(0.35 \%)$ & $3(0.21 \%)$ & $23(0.39 \%)$ & $1.97(0.59,6.56)$ & 0.27 \\
\hline Asian & $124(1.67 \%)$ & $30(2.06 \%)$ & $94(1.58 \%)$ & $0.80(0.53,1.22)$ & 0.30 \\
\hline Native Hawaiian or Other Pacific Islander & $4(0.05 \%)$ & $0(0.00 \%)$ & $4(0.07 \%)$ & NA & NA \\
\hline Other & $98(1.32 \%)$ & $18(1.24 \%)$ & $80(1.34 \%)$ & $1.14(0.68,1.91)$ & 0.62 \\
\hline Unknown & $105(1.42 \%)$ & $23(1.58 \%)$ & $82(1.38 \%)$ & $0.92(0.57,1.46)$ & 0.71 \\
\hline \hline
\end{tabular}

\begin{tabular}{|l|c|c|c|c|c||}
\hline \multicolumn{5}{|c||}{ Investigation into Staff Helpfulness by Race, among Males } \\
\hline & $\begin{array}{c}\text { Total } \\
(\mathbf{n}=\mathbf{5 5 1 3})\end{array}$ & $\begin{array}{c}\text { Staff Not } \\
\text { Always Helpful } \\
(\mathbf{n = 9 6 0 )}\end{array}$ & $\begin{array}{c}\text { Staff Always } \\
\text { Helpful } \\
(\mathbf{n}=\mathbf{4 5 5 3})\end{array}$ & OR (95\% CI) & P-value \\
\hline Race & \multicolumn{5}{|c||}{0.25} \\
\hline Caucasian/White & $4484(81.34 \%)$ & $762(79.38 \%)$ & $3722(81.75 \%)$ & Reference & -- \\
\hline Black or African American & $794(14.40 \%)$ & $154(16.04 \%)$ & $640(14.06 \%)$ & $0.85(0.70,1.03)$ & 0.10 \\
\hline 2 or more races & $53(0.96 \%)$ & $8(0.83 \%)$ & $45(0.99 \%)$ & $1.15(0.54,2.45)$ & 0.71 \\
\hline American Indian or Alaskan Native & $30(0.54 \%)$ & $2(0.21 \%)$ & $28(0.61 \%)$ & $2.87(0.68,12.06)$ & 0.15 \\
\hline Asian & $50(0.91 \%)$ & $13(1.35 \%)$ & $37(0.81 \%)$ & $0.58(0.31,1.10)$ & 0.10 \\
\hline Native Hawaiian or Other Pacific Islander & $3(0.05 \%)$ & $0(0.00 \%)$ & $3(0.07 \%)$ & NA & NA \\
\hline Other & $55(1.00 \%)$ & $13(1.35 \%)$ & $42(0.92 \%)$ & $0.66(0.35,1.24)$ & 0.20 \\
\hline Unknown & $44(0.80 \%)$ & $8(0.83 \%)$ & $36(0.79 \%)$ & $0.92(0.43,1.99)$ & 0.83 \\
\hline
\end{tabular}

These results are consistent with results reported by Goldstein et al, where Black/African American patients, in general, reported better experiences on the overall HCAHPS survey in comparison to Caucasian/ White patients $(18,20-22)$. Nonetheless, these results represent a departure from the current literature on racial disparities in pain management in the United States. Research shows that physicians usually underestimate the severity of pain if the patient is from a minority group $(23,24)$. Minorities are generally less likely to receive adequate care for pain management (25). The discrepancy can potentially be explained by the different expectations between different racial and ethnic groups in terms of pain management. Although most clinical quality and access indicators show superior health care for non-Hispanic Caucasian/White patients, Black/African American and Hispanic patients assess their interactions with providers more positively than
non-Hispanic Caucasian/White patients (26). Another study found that, generally, Black/African American patients give physicians higher ratings than do Caucasian/ White patients (27).

However, we also identified corresponding associations between response to HCAHPS pain questions and patient race/ethnicity: Hispanic and Black/African American patients were each less likely to respond to the HCAHPS pain questions. There are 2 possible explanations for this response variance: (a) Hispanic and Black/African American patients were less likely to be treated for pain; or (b) Hispanic and Black/African American patients with negative experiences were less likely to respond to HCAHPS (at either the full-survey or pain-question levels).

The HCAHPS instruments used with the study population include a pain screening question: "During this hospital stay, did you need medicine for pain?" Patients 
Table 4. Demographics of Survey responder's vs Non-responders

\begin{tabular}{|c|c|c|c|c|c|}
\hline \multicolumn{6}{|c|}{ Demographics of Pain Question Survey Responders vs Non-Responders } \\
\hline & $\begin{array}{c}\text { Total } \\
(\mathrm{n}=\mathbf{1 0 7 , 2 8 7})\end{array}$ & $\begin{array}{l}\text { Responders } \\
(n=13026)\end{array}$ & $\begin{array}{c}\text { Non-responders } \\
(\mathrm{n}=94261)\end{array}$ & OR (95\% CI) & $P$-value \\
\hline Ethnicity & & & & & $<0.001$ \\
\hline Not Hispanic/Latino & $101009(94.15 \%)$ & $12416(95.32 \%)$ & $88593(93.99 \%)$ & Reference & -- \\
\hline Hispanic & $3941(3.67 \%)$ & $255(1.96 \%)$ & $3686(3.91 \%)$ & $2.03(1.78,2.30)$ & $<0.001$ \\
\hline Not Reported & $2337(2.18 \%)$ & $355(2.73 \%)$ & $1982(2.10 \%)$ & $0.78(0.70,0.88)$ & $<0.001$ \\
\hline Race & & & & & $<0.001$ \\
\hline Caucasian/White & $64320(59.95 \%)$ & $10103(77.56 \%)$ & $54217(57.52 \%)$ & Reference & -- \\
\hline Black or African American & $34635(32.28 \%)$ & $2206(16.94 \%)$ & $32429(34.40 \%)$ & $2.74(2.61,2.87)$ & $<0.001$ \\
\hline 2 or more races & $1928(1.80 \%)$ & $175(1.34 \%)$ & $1753(1.86 \%)$ & $1.87(1.60,2.18)$ & $<0.001$ \\
\hline American Indian or Alaskan Native & $585(0.55 \%)$ & $57(0.44 \%)$ & $528(0.56 \%)$ & $1.73(1.31,2.70)$ & $<0.001$ \\
\hline Asian & $1569(1.46 \%)$ & $176(1.35 \%)$ & $1393(1.48 \%)$ & $1.48(1.26,1.73)$ & $<0.001$ \\
\hline Native Hawaiian or Other Pacific Islander & $98(0.09 \%)$ & $7(0.05 \%)$ & $91(0.10 \%)$ & $2.42(1.12,5.23)$ & 0.02 \\
\hline Other & $2794(2.60 \%)$ & $153(1.17 \%)$ & $2641(2.80 \%)$ & $3.22(2.73,3.79)$ & $<0.001$ \\
\hline Unknown & $1358(1.27 \%)$ & $149(1.14 \%)$ & $1209(1.28 \%)$ & $1.51(1.27,1.80)$ & $<0.001$ \\
\hline Sex & & & & & -- \\
\hline Female & 60015 (55.94\%) & $7465(57.31 \%)$ & $52550(55.75 \%)$ & Reference & -- \\
\hline Male & $47207(44.00 \%)$ & $5561(42.69 \%)$ & $41646(44.18 \%)$ & $1.06(1.03,1.10)$ & 0.001 \\
\hline Unknown & $65(0.06 \%)$ & $0(0.00 \%)$ & $65(0.07 \%)$ & NA & NA \\
\hline
\end{tabular}

who respond "No" to this question are instructed to skip the 2 pain-domain questions. Therefore, if fewer Hispanic and Black/African American patients need pain treatment, they would be underrepresented among HCAHPS pain-domain respondents. The combination of Hispanic and Black/African American patients having less pain and being more responsive to pain treatment would suggest that pain is notably less problematic among these demographic groups. Such a conclusion defies reason and is not supported by the literature. Another possibility is that patients respond "No" when asked if they needed medicine for pain because they do not recall all of the events during their hospitalization. Since this survey is taken after discharge from the hospital, there may be a bias based on patient recall.

It is also possible that both principal associations (HCAHPS Responses - Demographics and Response Rate - Demographics) are related to an underreporting of negative experiences by Hispanic and Black/African American patients. That is, if Hispanic and Black/African American patients who would respond negatively to the HCAHPS pain questions choose to withhold their responses (either to the entire HCAHPS survey or to those specific questions), those demographic groups would be underrepresented among HCAHPS pain question re- spondents. Further, responses from those demographic groups would be biased towards positive responses. Racial and ethnic differences in response rates to national adult surveys have been examined in prior research (28). The analysis by Sykes et al was complicated by a widespread lack of response-rate reporting and large variability in response rates across studies. The authors attribute variations in response rates to the design of surveys and the methods by which the surveys were introduced. They did not identify consistent trends in response by race/ethnicity across all surveys, but did note meaningful differences in response rates within many surveys.

However, racial and ethnic differences in response rates to the HCAHPS survey do not appear to have been previously reported, including by studies reporting racial/ethnic differences in HCAHPS-reported patient satisfaction (20-22). Discrepancies in the demographic makeup of HCAHPS respondents, HCAHPS samples, and overall hospital patient populations could lead to demographically-biased inaccuracies. HCAHPS patient satisfaction measures are important quality measures and have a critical role in US hospital reimbursement. Because of this, patient care and organizational decisions within hospitals and health systems are often 
based upon HCAHPS data. Biases in the data can therefore lead to inadvertent biases in care and resource allocation, indicating the need for further research in this area.

\section{Limitations and Future Directions}

One of the limitations of this study is that it is a single institutional study. However, because the university hospital is large and located in an urban area and serves a diverse population, we believe the results may reflect the health care system as a whole. Another limitation of this study is that only $12 \%(13,026$ responded out of 107,287 total discharges) of the discharged population responded to the pain questions on the survey during our timeframe. Further research is needed to determine whether nonrespondents differed in their interpretation of the survey or understanding of questions or had a systematically different health care experience. Additionally, of the $12 \%$ of respondents, fewer than $2 \%$ classified themselves as Hispanic. This population may be an underrepresentation, as the total Hispanic popu- lation in America as of 2016 was 17.8\% (29). However, it cannot be determined if this underrepresentation is due to a lower Hispanic population at the university hospital, or if the Hispanic population has a significantly lower response rate to the survey.

Continued demographic studies should also focus on education, employment status, and socioeconomic status. Of note, a new, current, HCAHPS survey has been published by CMS and will go into effect October 1, 2019 (30). The previous version of this new questionnaire reported communication of pain between providers and patients, however, these questions have been removed. This new survery will no longer include questions specific to pain management.

\section{Acknowledgments}

We wish to thank Dr. Vimal Desai for his contributions to a precursor study and to this study's conceptualization; and Drs. Theresa Williamson and Jacquelyn Corley, for their thoughtful reviews of this work.

\section{References}

1. Glickman SW, Boulding W, Manary M, et al. Patient satisfaction and its relationship with clinical quality and inpatient mortality in acute myocardial infarction. Circ Cardiovasc Qual Outcomes 2010; 3:188-195.

2. Boulding W, Glickman SW, Manary MP, Schulman KA, Staelin R. Relationship between patient satisfaction with inpatient care and hospital readmission within 30 days. Am J Manag Care 2011; 17:41-48.

3. Jha AK, Orav EJ, Zheng J, Epstein AM. Patients' perception of hospital care in the United States. N Engl J Med 2008; 359:1921-1931.

4. Patient Protection and Affordable Care Act, 42 USC 018001 (2010).

5. Geiger NF. On tying Medicare reimbursement to patient satisfaction surveys. Am J Nurs 2012; 112:11.

6. Centers for Medicare \& Medicaid Services. Total Performance Scores 2017. www.medicare.gov/hospitalcompare/ data/total-performance-scores.html. Date Published 1/24/2018. Date Accessed 2/1/2018.
7. Centers for Medicare \& Medicaid Services. Patient- and caregiver-centered experience of care/care coordination domain 2017. www.medicare.gov/HospitalCompare/Data/patient-and-caregivercentered-experience-of-care-care-coordination-domain.html. Date Published 1/24/2018. Date Accessed 2/1/2018.

8. Kirsch B BH, Zablotsky D. Management strategy: Identifying pain as the fifth vital sign. VHS] 2000; \{AU: volume?\}:49-59. \{AU: This citation has multiple errors: authors, title, missing volume, maybe incorrect page numbers\}

9. Phillips DM. JCAHO pain management standards are unveiled. JAMA 2000; 284:428-429.

10. Department of Veterans Affairs. VHA Directive 2003-021: Pain Management. www.doctordeluca.com/Library/Pain/ VaDirectives4PainManagemento3.pdf. Date Published 05/02/2003. Date Accessed 2/1/2018.

11. Phillips S, Gift M, Gelot S, Duong M Tapp $H$. Assessing the relationship between the level of pain control and patient satisfaction. J Pain Res 2013;
6:683-689.

12. Tighe PJ, Fillingim RB, Hurley RW. Geospatial analysis of hospital consumer assessment of healthcare providers and systems pain management experience scores in US hospitals. Pain 2014; 155:1016-1026.

13. McFarland DC, Shen MJ, Holcombe RF. Predictors of patient satisfaction with inpatient hospital pain management across the United States: A national study. J Hosp Med 2016; 11:498-501.

14. Li L, Lee NJ, Glicksberg BS, Radbill BD, Dudley JT. Data-driven identification of risk factors of patient satisfaction at a large urban academic medical center. PLoS One 2016; 11:e0156076.

15. Paasche-Orlow MK, Wolf MS. The causal pathways linking health literacy to health outcomes. Am J Health Behav 2007; 31:S19-S26.

16. Williams DR, Yu Y, Jackson JS, Anderson NB. Racial differences in physical and mental health: Socio-economic status, stress and discrimination. J Health Psychol 1997; 2:335-351.

17. Iannuzzi JC, Kahn SA, Zhang L, Gestring 
ML, Noyes K, Monson JR. Getting satisfaction: Drivers of surgical Hospital Consumer Assessment of Health Care Providers and Systems survey scores. J Surg Res 2015; 197:155-161.

18. Goldstein E, Elliott MN, Lehrman WG Hambarsoomian K, Giordano LA. Racial/ethnic differences in patients' perceptions of inpatient care using the HCAHPS survey. Med Care Res Rev 2010; 67:74-92.

19. Centers for Medicare \& Medicaid Services. The HCAHPS Survey - Frequently Asked Questions. www.cms.gov/Medicare/Quality-Initiatives-Patient-Assessment-Instruments/HospitalQualityInits/Downloads/HospitalHCAHPS FactSheet201007.pdf. Date Accessed 04/10/2013.

20. Peres-da-Silva A, Kleeman LT, Wellman SS, et al. What factors drive inpatient satisfaction after knee arthroplasty? J Arthroplasty 2017; 32:1769-1772.

21. Figueroa JF, Zheng J, Orav EJ, Jha AK.
Across US hospitals, black patients report comparable or better experiences than white patients. Health Aff 2016; 35:1391-1398.

22. Shaterian A, Gandy J, Lalezari S, Smith $S$, Paydar K. Patient race and provider predict patient satisfaction following post-mastectomy breast reconstruction. World J Plast Surg 2016; 5:114-123.

23. Cleeland CS, Gonin R, Baez L, Loehrer $P$, Pandya KJ. Pain and treatment of pain in minority patients with cancer: The Eastern Cooperative Oncology Group Minority Outpatient Pain Study. Ann Intern Med 1997; 127:813-816.

24. Anderson KO, Mendoza TR, Valero V, et al. Minority cancer patients and their providers. Cancer 2000; 88:1929-1938.

25. Anderson KO, Green CR, Payne R. Racial and ethnic disparities in pain: Causes and consequences of unequal care. J Pain 2009; 10:1187-1204.

26. Dayton E, Zhan C, Sangl J, Darby C, Moy E. Racial and ethnic differences in patient assessments of interactions with providers: Disparities or measurement biases? Am J Med Qual 2006; 21:109-114.

27. Elliott MN, Haviland AM, Kanouse DE, Hambarsoomian K, Hays RD. Adjusting for subgroup differences in extreme response tendency in ratings of health care: Impact on disparity estimates. Health Serv Res 2009; 44:542-561.

28. Sykes LL, Walker RL, Ngwakongnwi E, Quan H. A systematic literature review on response rates across racial and ethnic populations. Can J Public Health 2010; 101:213-219.

29. US Census Bureau. Hispanic Heritage Month 2017. 2017. www.census. gov/newsroom/facts-for-features/2017/ hispanic-heritage.html. Date accessed 2/1/2018.

30. HCAHPS: Hospital Consumer Assessment of Healthcare Providers and Systems 2019. www.hcahpsonline.org/. Date accessed 4/11/2019. 